\title{
Implication of integrin a $2 \beta 1$ in anoikis of SK-Mel-147 human melanoma cells: a non-canonical function of Akt protein kinase
}

\author{
Nadezhda I. Kozlova', Galina E. Morozevich ${ }^{1}$, Natalia A. Ushakova ${ }^{1}$ and Albert E. \\ Berman $^{1}$ \\ ${ }^{1}$ VN Orekhovich Institute of Biomedical Chemistry, Moscow, Russia \\ Correspondence to: Albert E. Berman, email: 1938berman@gmail.com \\ Keywords: integrins, a2 $\beta 1$, anoikis, tumor growth, Akt isoforms \\ Received: December 12, $2018 \quad$ Accepted: February 15, 2019 Published: March 05, 2019 \\ Copyright: Kozlova et al. This is an open-access article distributed under the terms of the Creative Commons Attribution License \\ 3.0 (CC BY 3.0), which permits unrestricted use, distribution, and reproduction in any medium, provided the original author and \\ source are credited.
}

\section{ABSTRACT}

Suppression of anoikis, a kind of apoptosis caused by disruption of contacts between cell and extracellular matrix, is an important prerequisite for cancer cell metastasis. In this communication, we demonstrate that shRNA-mediated depletion of $\mathbf{a} 2$ integrin subunit induces anoikis and substantially decreases colony-forming potential in SK-Mel-147 human melanoma cells. Suppression of a2 $\beta 1$ upregulates the levels of pro-apoptotic protein p53 and cyclin-dependent kinase inhibitors p21 and p27. Concomitantly, we detected decrease in the levels of anti-apoptotic protein Bcl2 and cell cycle regulator c-Myc. Moreover, depletion of a2 $\beta 1$ reduces the activity of protein kinase Erk, while increases activity of Akt kinase. Pharmacological inhibition of P3IK kinase, an upstream activator of Akt, greatly enhanced anoikis in control cells while reduced that in cells with decreased levels of a $2 \beta 1$. Of three isoforms of Akt, down-regulation of Akt1 greatly diminished anoikis of cells depleted of a $2 \beta 1$, while down-regulation of Akt2 and Akt3 sharply increased anoikis in these cells. These findings were supported by the data of pharmacological inhibition of the Akt isoforms. Our results demonstrate for the first time that anoikis induced by a2 21 integrin knockdown can be attenuated by Akt1 inhibition.

\section{INTRODUCTION}

The growth and malignant progression of tumor cells greatly depends on their interaction with the extracellular matrix (ECM). A hallmark of the malignant phenotype is the capacity of tumor cells to grow in the absence of ECM contacts. Normal cells detached from the ECM, undergo a variant of apoptosis termed anoikis. A critical early phase of tumor progression is the development of mechanisms that enable cells to overcome anoikis [1-3].

Experimental data show that the ECM regulates all aspects of oncogenic transformation. This regulation occurs via a successive trafficking of the matrixderived signals delivered to nucleus through a chain of intracellular molecules with subsequent modification of gene activity referred to as signal transduction. Key mediators in signal transduction are the integrins, cell surface receptors that directly associate with the matrix proteins and initiate signaling. The majority of studies indicate that integrins are involved in the mechanisms underlying cell behaviors such as proliferation, motility, differentiation, and apoptosis; all of which are modified in the growth and progression of tumors [4-7].

The most common and vital integrins for mammalian cells are fibronectin-binding $\alpha 5 \beta 1$, the collagen-binding receptor $\alpha 2 \beta 1$ and integrin $\alpha \mathrm{v} \beta 3$ with diverse ligand specificity. These receptors are the subject of several studies aimed at clarifying the role of integrin-mediated signaling in growth and progression of tumors [8-10].

Only a few reports have addressed the role of integrin $\alpha 2 \beta 1$ in anoikis. Along with evidence for the involvement of this receptor in protecting cells from anoikis, there are many reports showing apoptogenic activity of $\alpha 2 \beta 1$ in several cell types [11-13]. One possible explanation is that $\alpha 2 \beta 1$, like other integrins, can initiate diverse signaling pathways, thereby inducing a variety 
of responses in different cells depending on factors like their physiological status, developmental stage, interaction with external and internal factors. As signal transduction pathways initiated by integrin $\alpha 2 \beta 1$ are not well understood, the present study seeks to demonstrate that integrin $\alpha 2 \beta 1$ can be implicated in the protection of tumor cells from anoikis through the inhibition of Akt1, one of the Akt kinase izoforms.

\section{RESULTS}

\section{Inhibition of integrin $\alpha 2 \beta 1$ signaling increased anoikis of SK-Mel-147 melanoma cells and decreased their clonal activity}

To evaluate the implication of $\alpha 2 \beta 1$ in cell-matrix detachment-induced stress, we explored the effects exerted on anoikis by down-regulation of this receptor. Signal activity of integrin $\alpha 2 \beta 1$ was inhibited by suppressing its expression with the $\alpha 2$-specific shRNA. Investigation of two plasmid clones, expressing $\alpha 2$-specific shRNA, indicated that they both markedly reduced the expression of $\alpha 2 \beta 1$ although the D3 clone was more effective (Figure 1).
Cells cultured under standard conditions, form and adhere to the substrate consisting of adhesion proteins secreted by these cells (fibronectin, collagen, laminin, etc.). As shown in Figure 2A, SK-Mel-147 cells do not undergo apoptosis irrespectively of their $\alpha 2 \beta 1$ level. However, when incubated on a non-adhesive substrate, the cells with lower levels of $\alpha 2 \beta 1$ are more prone to anoikis than control cells with higher $\alpha 2 \beta 1$; while in control cultures the level of anoikis was relatively small (approximately 17\%), in cultures with $\alpha 2$-specific shRNA, the percentage of apoptotic cells increased up to $38 \%$ of the total cell population (Figure 2B). Therefore, $\alpha 2$ downregulation triggers death of SK-Mel-147 cells only on a non-adhesive substrate.

A hallmark of oncogenic transformation of cells is their capacity to form colonies in semi-solid media. A prerequisite for development of this phenotype is resistance to anoikis; however, acquisition of this property depends on the degree of resistance [14]. To characterize the role of $\alpha 2 \beta 1$ in oncogenic activity of tumor cells, we analyzed the impact of $\alpha 2 \beta 1$ knockdown on the ability of SK-Mel-147 cells to form colonies in methylcellulose gel. The depletion of $\alpha 2 \beta 1$ led to a sharp reduction in the

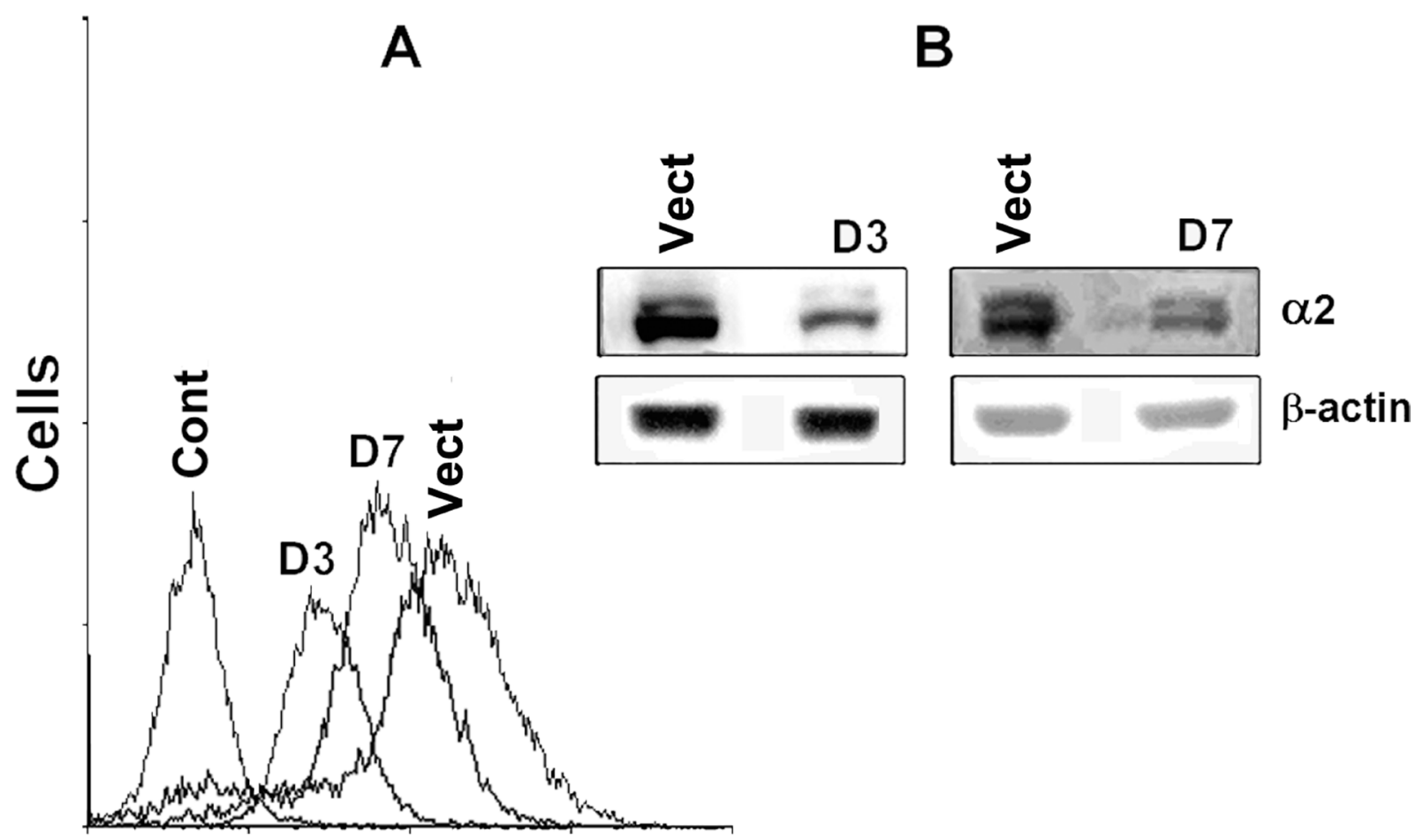

\section{Fluorescence}

Figure 1: Transduction of SK-Mel-147 cells with $\alpha 2$-specific shRNA effectively inhibits expression of $\alpha 2 \beta 1$ integrin. The cells were transduced with a lentiviral plasmid vector pLKO.1-puro containing $\alpha 2$ shRNA (clones D3, D7) or with the control vector (the "empty" vector) and selected using puromycin. (A) FACS analysis of $\alpha 2 \beta 1$ cell surface expression; Control: cells were transduced with the "empty" pLKO.1-puro and stained with FITC-conjugated anti-mouse IgG; D3, D7: cells were transduced with D3 or D7 clones containing $\alpha 2$ shRNA, treated with $\alpha 2 \beta 1$ monoclonal antibodies and stained with FITC-conjugated anti-mouse IgG; Vect: cells were transduced with the "empty" vector, treated and stained as in D3. (B) Western-blotting of the cellular lysate proteins. Vect: the cells were transduced with the "empty" vector; D3, D7: the cells were transduced with clones containing $\alpha 2$ shRNA. 
number of colonies formed by SK-Mel-147 cells after their cultivation in a methylcellulose gel for 14 days (Figure $2 \mathrm{C}, 2 \mathrm{D})$. This result corroborates anoikis enhancement in SK-Me-147 cells in response to $\alpha 2 \beta 1$ knockdown.

\section{Signaling pathways that mediate effects caused by inhibition of $\alpha 2 \beta 1$}

To clarify the mechanisms mediating the effect of integrin $\alpha 2 \beta 1$ on anoikis, we analyzed the expression of proteins known to be involved in signal transduction and regulation of diverse cellular functions. As shown in Figure 3A, down-regulation of $\alpha 2 \beta 1$ leads to a sharp increase in expression of apoptotic p53 and decrease of anti-apoptotic protein BCL-2. In addition, we have found a significant increase in the expression of cell cycle inhibitors, proteins p21 and p27. All of these proteins are known to play important roles in the mechanisms of proliferation and cell survival $[15,16]$.

These proteins control events which occur in the nucleus, (e.g. the terminal phase of signal transduction) and, therefore, in addition to integrins, other cell receptors and intracellular metabolites can induce these signals. In the case of integrins, more specific are "early" steps of signal transduction which are proximal to cell membranes. Of these pathways, the best characterized are those, mediated by protein kinases IP3-K/Akt and by the MAPK family of kinases, including ERK $[17,18]$. To clarify the involvement of these pathways in integrin-mediated signaling, we determined the changes in expression and activity of Akt and ERK1/2 (42- and $44 \mathrm{kDa}$ ERK isomers) kinases which were induced in the $\alpha 2 \beta 1$ knockdowned SK-Mel-147 cells. Kinase expression was assessed by western blot of cell lysates using antibodies to the total enzyme protein and their activity was determined with antibodies specific to its active (phosphorylated) forms. As shown in Figure 3A, down-regulation of $\alpha 2 \beta 1$ had no effect on the total protein expression of Akt and ERK in melanoma cells, but modified the activity of these kinases. While the cellular amount of phosphorylated ERK isoforms was reduced, the active Akt form substantially increased.

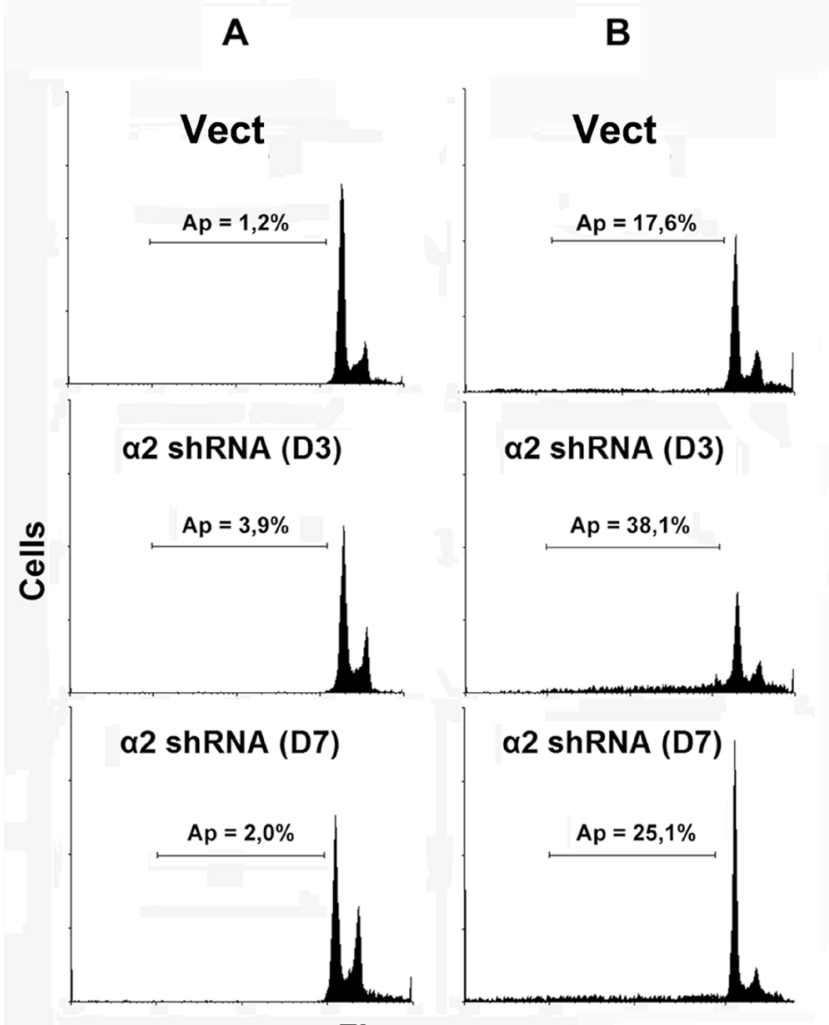

Fluorescence
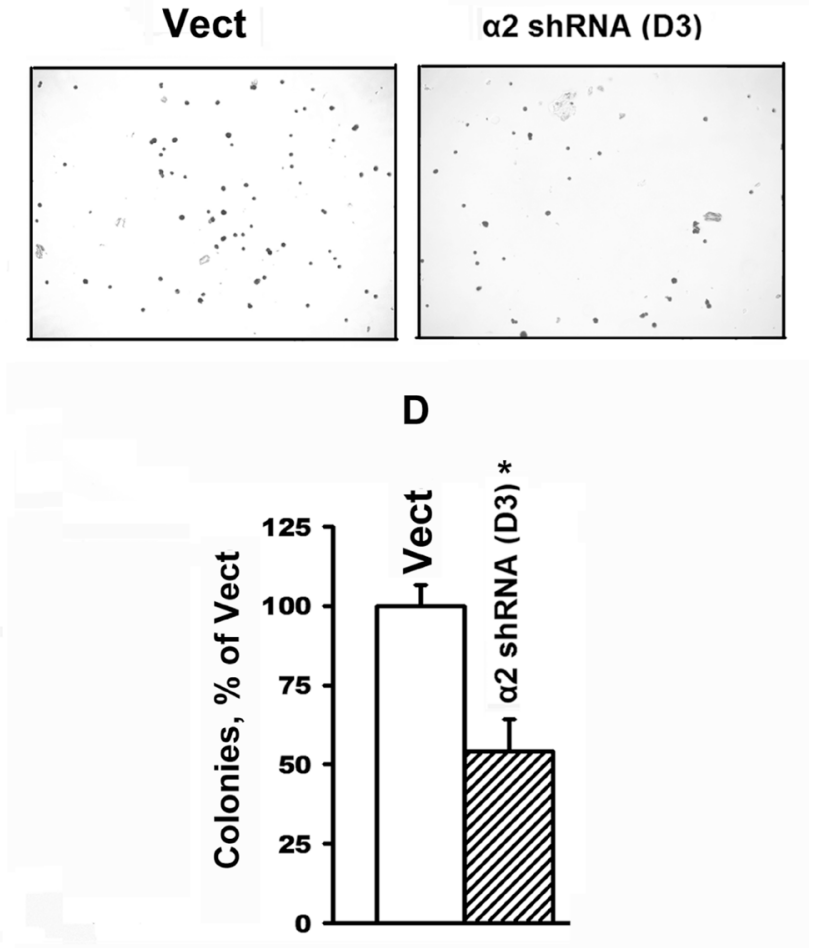

Figure 2: Transduction with $\alpha 2$ shRNA increases anoikis of SK-Mel-147 cells. Cells transduced with the empty or $\alpha 2$ shRNAcontaining vectors were cultured in a 6-well plate untreated (A) or coated with a non-adhesive substrate - poly-HEMA (B) and prepared for flow cytometry. Typical histograms are presented; Ap: apoptotic cells, horizontal lines indicate populations of cells with a sub-diploid (sub-G1) DNA content. Content of apoptotic cells (\%) in the total cell population is shown. (C, D) Effect of $\alpha 2 \beta 1$ down-regulation on clonal capacity of SK-Mel-147 cells. Cells tranduced with the empty (Vect) or $\alpha 2$ shRNA-containing vectors (D3, D7), were treated as described in Materials and Methods. C: shown is a typical experiment; $\mathrm{D}$ : results of three independent experiments are shown (M $\pm \mathrm{SEM}$ ); ${ }^{*} p<0.01$, relative to Vect. 


\section{Non-canonical function of Akt1 in anoikis of SK- Mel-147 cells}

The finding of diminished ERK activity in cells with elevated anoikis levels is consistent with the known protective functions of this kinase against the various stresses [18-20]. Since Akt kinase also plays a key role in survival and rescuing the cells under numerous stressful conditions, including anoikis [21,22], the finding of its activation in cells with a markedly enhanced anoikis might result from the non-canonical Akt functions in these cells, consisting in promoting rather than suppressing anoikis. This assumption agrees with our recently obtained results showing that stimulating effect of $\alpha 2 \beta 1$ integrin on the invasion of Sk-Mel-147 cells is mediated through a mechanism based on inhibition of Akt1, one of the isoforms of this protein kinase [23]. But it could not be excluded that the observed increase in Akt activity is a feature accompanying down-regulation of $\alpha 2 \beta 1$ in SKMel-147 cells and is not related to mechanisms controlling anoikis.
To verify these possibilities, we compared the levels of $\alpha 2 \beta 1$ and active Akt in $\alpha 2$ shRNA-treated cells after they had been cultured on adhesive and non-adhesive substrates.

Obviously, the population of cells treated with $\alpha 2$ shRNA is heterogeneous and contains, besides $\alpha 2$ shRNA transduced cells (with reduced level of $\alpha 2 \beta 1$ and increased level of pAkt), also a certain number of cells that have not undergone transduction and retained the original levels of $\alpha 2 \beta 1$ and pAkt. We hypothesized that if Akt stimulates cell death on a non-adhesive substrate, then cells with lower level of this kinase have a selective advantage and will survive on this substrate. At the same time, some cells with higher Akt levels will die and as such would not contribute to $\alpha 2 \beta 1$ - and Akt-specific signals in westernblotting. Therefore, one could expect that population of $\alpha 2$ shRNA treated cells, incubated on poly-HEMA, will have higher level of $\alpha 2 \beta 1$ and lower level of pAkt than the same population incubated on an adhesive substrate.

As shown in Figure 3B, the population of $\alpha 2$ shRNA-treated cells grown for $24 \mathrm{~h}$ on poly-HEMA (as
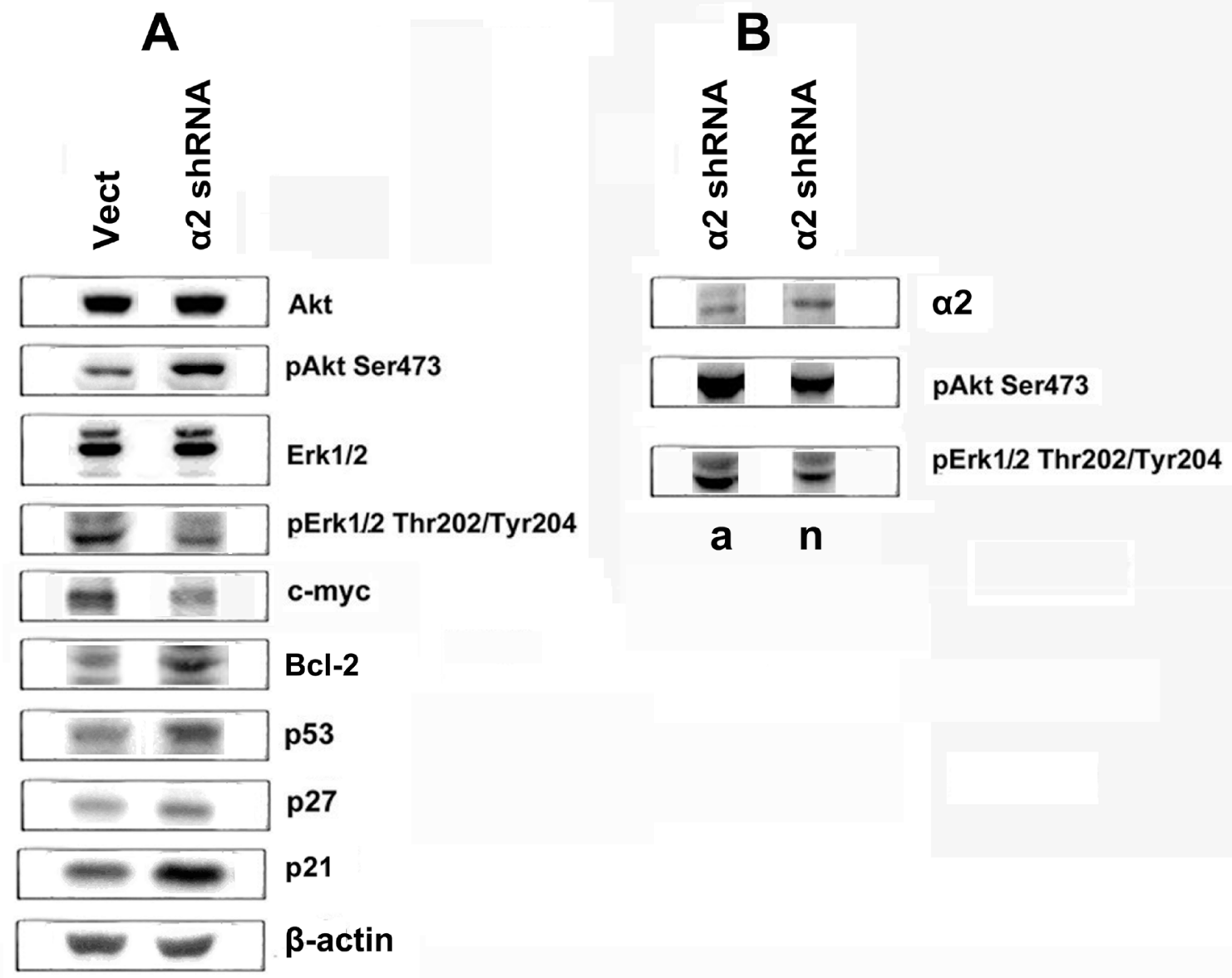

Figure 3: Effect of $\alpha 2 \beta 1$ knockdown on expression of signaling proteins in SK-Mel-147 cells. (A) The cells were transduced with the empty (Vect) or $\alpha 2$ shRNA-containing vectors, and cell lysate proteins were run on SDS-PAGE and western-blotted as described in Materials and Methods. (B) $\alpha 2$ shRNA-transduced cells were grown for $24 \mathrm{~h}$ on adhesive (a) or non-adhesive (n) substrates and cell lysate proteins were analyzed as in A. The blots were probed with 1:1000 dilution of antibodies to the specified proteins, except for 1:300 dilution of c-Myc antibodies. 
compared with cells grown for the same time on adhesive substrate) demonstrated increased $\alpha 2 \beta 1$ and reduced phosopho-Akt levels, while the relative level of active ERK remained unchanged.

To obtain direct evidence that Akt mediates the death of cells deprived of substrate contacts, the effect of LY 294002, a specific Akt inhibitor, on anoikis was determined in SK-Mel-147 cells with unchanged (control) and reduced $\alpha 2 \beta 1$ expression. We supposed that if enhancement of melanoma cell anoikis, induced by $\alpha 2 \beta 1$ knockdown, occurs via activation of the PI3K/Akt signal pathway, inhibition of this kinase should neutralize the stimulating effect or even attenuate anoikis. Figure 4 demonstrates that while LY294002 markedly increased anoikis of control cells, it diminished anoikis in $\alpha 2 \beta 1$-knockdown cells to a comparable level of anoikis in the control cells. To compare, the Erk inhibitor PD98059 markedly increased anoikis of both the control and $\alpha 2 \beta 1$-depleted cells.

In mammals, the AKT kinase family includes three members, AKT1, AKT2 and AKT3, which are encoded by three distinct genes. Recent studies revealed distinct roles of individual AKT members in development of malignant phenotype [24-27]. Notably, LY294002 does not exhibit isozyme-specific effects and suppresses the activity of all isoforms. One could speculate that increased level of phosphorylated Akt found in $\alpha 2 \beta 1$-depleted melanoma cells is the result of activation of one of the Akt isoforms, which unlike the other two promotes anoikis, i.e. manifests a non-canonical function.

To determine which of the Akt isozymes accounts for the observed effect, we investigated the changes in anoikis in response to inhibition of separate isoforms. As shown in Figure 5, treatment of the cells with compound XXIII resulted in a significant increase of anoikis in the vector-transduced cells and markedly attenuated anoikis in cells transduced with $\alpha 2$ shRNA. Compound XXIII has been previously shown to inhibit all Akt isozymes but possess a 21-23-fold higher potency against Akt1 compared to Akt2 and Akt3, respectively [28]. The concentrations of XXIII used in our experiments were comparable to the IC50 obtained when evaluating the apoptogenic activity of this compound in tumor lines of various origins [28]. Thus, the decrease in anoikis in cells treated with XXIII was most likely due to specific inhibition of Akt1. This suggestion was confirmed by the finding that the Akt2-specific inhibitor, compound XII, unlike XXIII, significantly increased anoikis of the cells transduced with $\alpha 2$ shRNA (Figure 5).

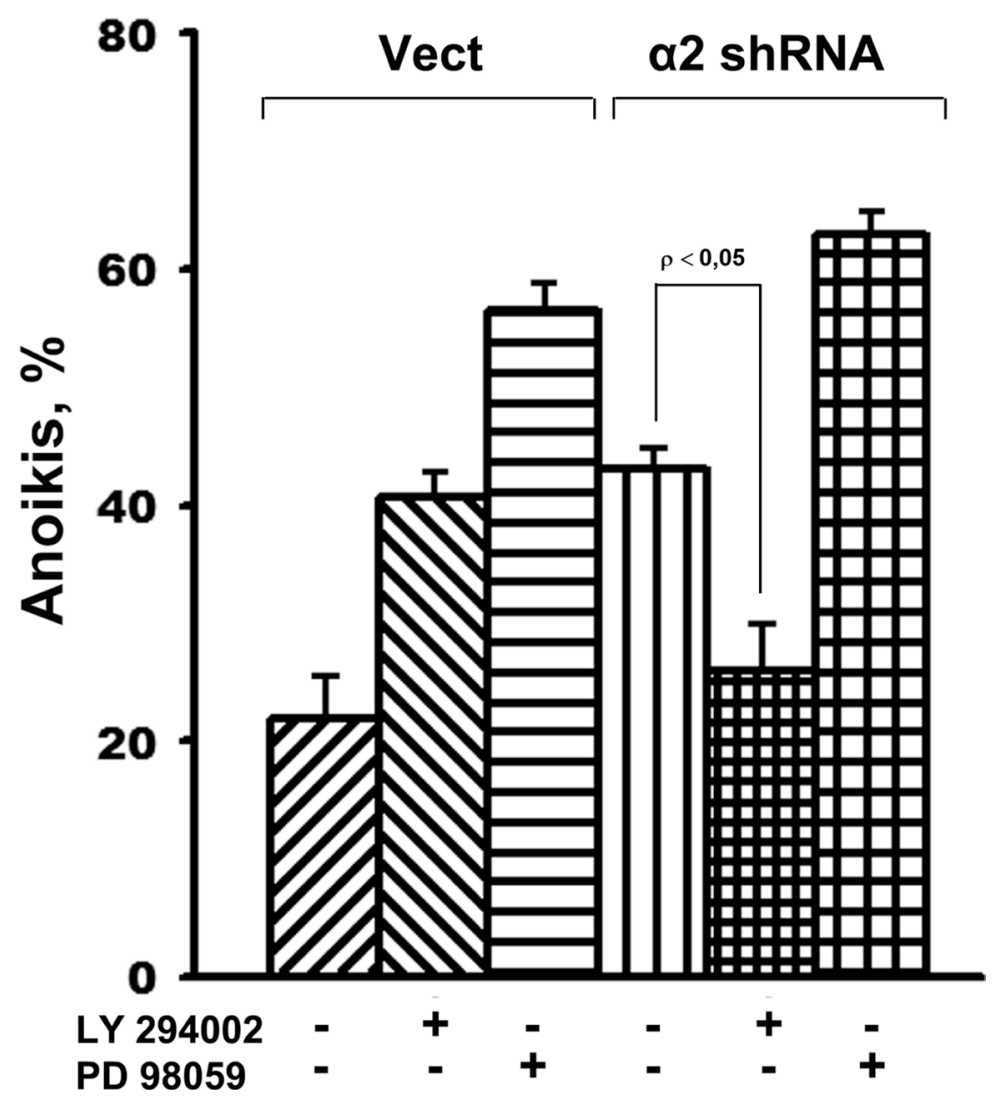

Figure 4: Inhibition of Akt kinase in SK-Mel-147 cells attenuates anoikis, caused by $\boldsymbol{\alpha} 2 \beta 1$ knockdown. Cells transduced with empty (Vect) or $\alpha 2$ shRNA-containing vectors were cultured on poly-HEMA as described in Materials and Methods. Prior to applying on poly-HEMA the cells were incubated for $24 \mathrm{~h}$ at $37^{\circ} \mathrm{C}$ in the medium supplemented with $25 \mu \mathrm{M}$ LY294002 or PD98059. Anoikis was determined from percentage of the sub-G1 population. The results of three independent experiments are shown (M $\pm \mathrm{SEM})$. 
The above studies were supplemented by assessing the changes in anoikis in response to knockdown of each of the three Akt isoforms caused by treating the cells with isoform-specific siRNAs. As shown in Figure 6A, 6B, silencing of either of the Akt isoform effectively down-regulated protein expression and activity of a corresponding isoform. Data in Figure 6C demonstrate that down-regulation of all three Akt isoforms strongly enhanced anoikis of cells transduced with the control vector, while only Aktl down-regulation lead to a significant decrease in anoikis in the cells transduced with the $\alpha 2$ shRNA.

\section{DISCUSSION}

The present investigation provides the evidence that integrin $\alpha 2 \beta 1$ performs a protective function against anchorage-dependent apoptosis (anoikis) in SK-Mel-147 melanoma cells. It was shown for the first time that this receptor triggers a protection mechanism based on inhibition, rather than activation, of Akt kinase. This noncanonical mechanism, not yet described for other integrins, is unexpected because Akt kinase has long been known as a stimulator of proliferation and viability of cells.
Published information on the role of the $\alpha 2 \beta 1$ and other integrins in the mechanisms of apoptosis, in particular of anoikis, are scarce and controversial. In different cell models, the same receptor can induce the opposite effects on anoikis. While in acute myeloleukemia cells, cell-surface activation of integrin $\alpha 4 \beta 1$ attenuated anoikis [29], its activation in osteosarcoma cells led to anoikis augmenting [30]. A key role of the $\alpha 5 \beta 1$ integrin in resistance to anoikis was demonstrated in breast and gastric cancer cells [31]. However, down-regulation, rather than up-regulation, of $\alpha 5 \beta 1$ promoted anoikis resistance in a similar model of gastric carcinoma cells [32] and in the cells derived from pancreatic carcinoma [33]. Results of studies on integrin $\alpha 2 \beta 1$ are also ambiguous. In our recent publication, down-regulation of the $\alpha 2 \beta 1$ integrin lead to a substantial increase of anoikis in human breast carcinoma cells [34]. In a gastric carcinoma line, cell death was shown to be resulted from lectininduced internalization and inactivation of $\alpha 2 \beta 1$ [12]. These findings indicate that the anti-anoikis function of $\alpha 2 \beta 1$, are not consistent with the studies on colorectal cancer cells [13]. The authors reported that blocking the expression of histone methyltransferase induced anoikis that was accompanied by a markedly enhanced expression

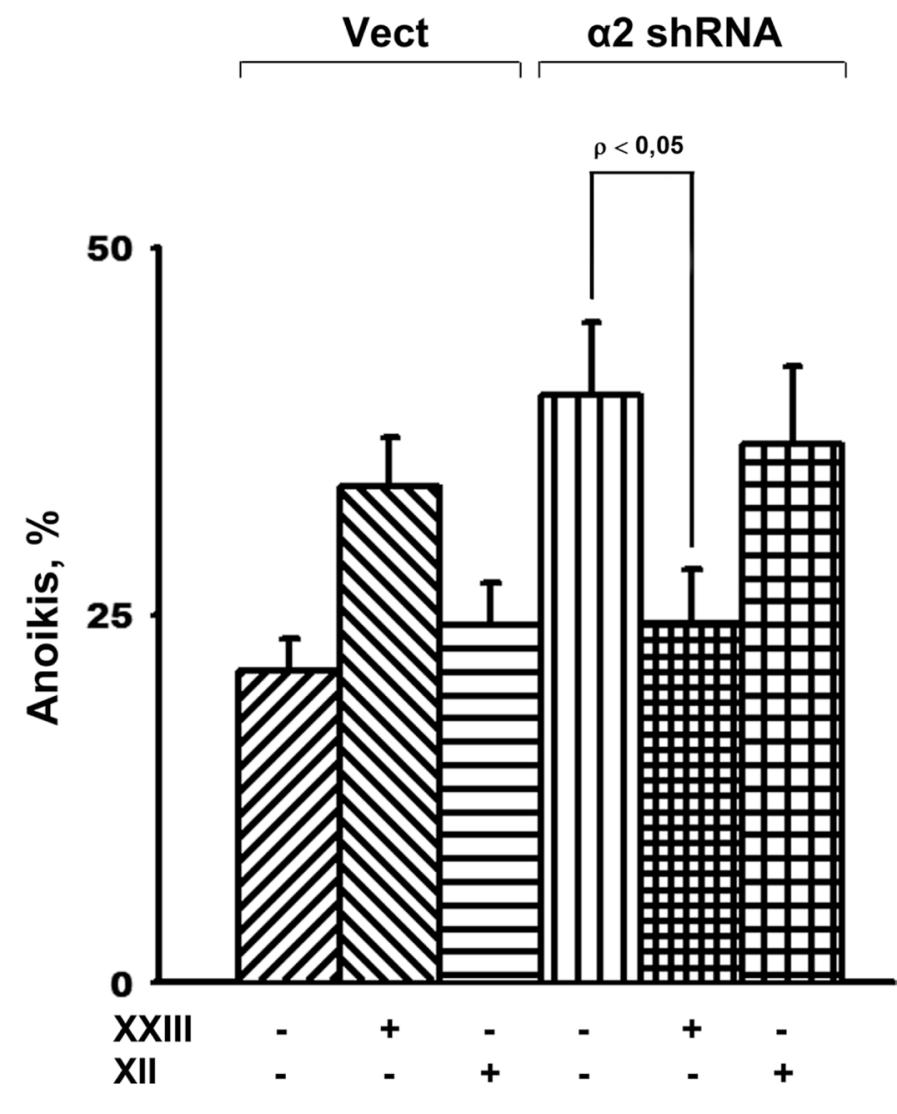

Figure 5: Effect of of Akt isoform inhibitors on anoikis of SK-Mel-147 cells. Cells transduced with empty (Vect) or $\alpha 2$ shRNAcontaining vectors were cultured on poly-HEMA as described in Materials and Methods. Prior to applying on poly-HEMA the cells were treated for $24 \mathrm{~h}$ at $37^{\circ} \mathrm{C}$ with $3 \mu \mathrm{M}$ Akt1-specific inhibitor XXIII or $5 \mu \mathrm{M}$ Akt2-specific inhibitor XII. Anoikis was determined from percentage of Trypan Blue-stained cells. The results of three independent experiments are shown $(\mathrm{M} \pm \mathrm{SEM})$. 
of $\alpha 2 \beta 1$, providing indirect evidence for the pro-anoikis capacity of this receptor. The ambiguity of studies on the role of integrins in anoikis is most likely accounted for by their implication in diverse signaling pathways shared with other receptors, which can control opposed cellular responses (proliferation, quiescence, aging, apoptosis, etc.) $[35-37]$.

Only few reports have addressed the detailed characterization of integrin-initiated signal transduction pathways induced upon loss of the cell-matrix contacts. According to Matsunaga, et al. [29], resistance of leukemia cells to anoikis is induced by integrin $\alpha 4 \beta 1$ through the PI-3K/Akt signal pathway and activation of anti-apoptotic protein BCL-2. Similar properties have been documented for integrin $\alpha 5 \beta 1$ in studies on breast carcinoma cells [8]; however, in this study, the evoked signals were transmitted through the MEK-ERK kinases and completed with the suppression of pro-apoptotic protein Bim.
Of considerable interest are the differences found between individual Akt isoforms in their impact on anoikis of melanoma cells. It appeared that of three Akt isoforms only Akt1 demonstrated a non-canonical function which consists in stimulating anoikis of melanoma cells with reduced expression of $\alpha 2 \beta 1$ integrin, while two other Akt isoforms had little effect on anoikis of these cells. This result corroborates our recent finding that inhibition of Akt1 (but not Akt2) enhances invasion of the SK-Mel-147 melanoma cells in vitro [23].

However, similar non-canonical functions of this kinase have been reported by others in various models of cancer progression. For example, in a breast adenocarcinoma line with high metastatic potential, the effect of TIS21 tumor suppressor, which consists in inhibiting the formation of invadopodia and, therefore, blocking the invasion, is realized through a mechanism mainly based on activation of Akt1, while changes in Akt2
A

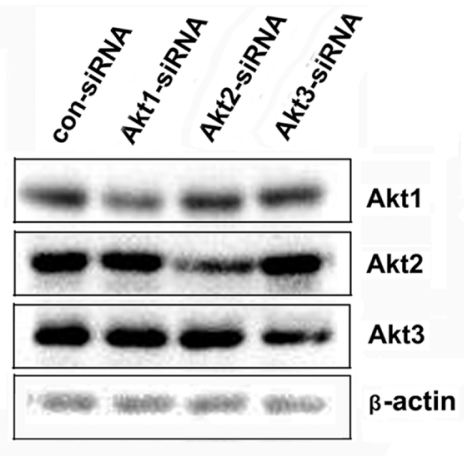

C

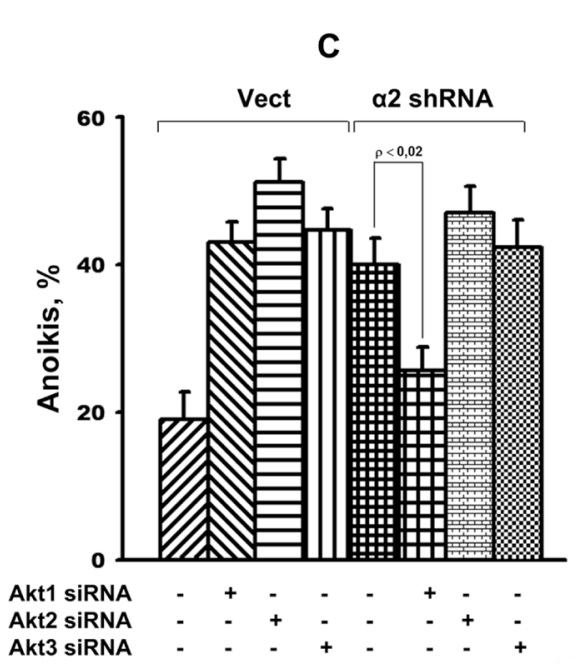

B

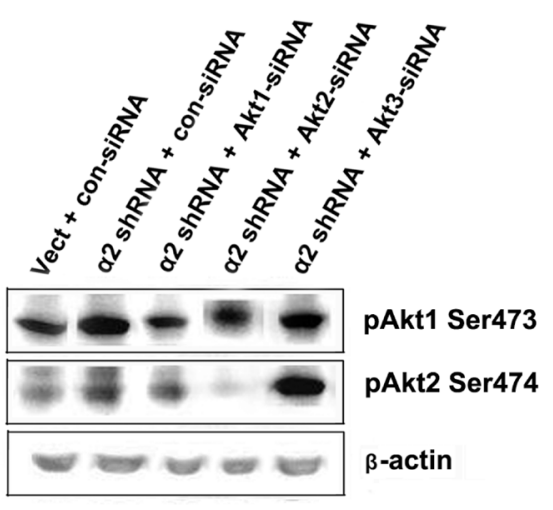

Figure 6: Effect of Akt isoform knockdown on anoikis of SK-Mel-147 cells. Cells were transduced with empty (Vect) or $\alpha 2$ shRNA-containing vectors and cultured on poly-HEMA as described in Materials and Methods. Prior to applying on poly-HEMA the cells were transfected with the Akt isoform-specific siRNAs as described earlier [45]. Cell lysate proteins were run on SDS-PAGE, westernblotted and probed with the total Akt isozyme specific antibodies (A) or specific to isozyme phosphorylated forms (B). Anoikis (C) was determined from percentage of Trypan Blue-stained cells. The results of five independent experiments are shown $(\mathrm{M} \pm \mathrm{SEM}$ ). 
expression had no impact on invadopodia formation and invasive activity [38].

The dual properties of Akt isoforms have been documented in several investigations. Akt1 was shown to stimulate the growth of breast carcinoma but inhibit its metastasis [26]. In contrast, Akt 2 enhanced invasion and metastasis of breast and ovarian carcinoma cells [27]. This finding has recently been confirmed on cells of the same origin [25]. It can be assumed that distinct cellular types differ in the expression of individual Akt isoforms, and therefore their responses to Akt-mediated signaling may be different.

Demonstrated in the present communication anoikis-promoting activity of Akt is not a unique property of this signal kinase. We have recently shown that anoikis induced by $\alpha 2 \beta 1$ down-regulation in the MCF-7 breast carcinoma cells, is mediated via activation of the ERK kinase [34] and this finding is consistent with a number of studies on various types of cancer cells [39-42]. Thus, integrin-induced signal pathways, evoked in the cells in response to a particular stress impacts are distinct in different neoplasia and need further explorations.

In conclusion, the mechanisms of almost all currently available targeted antitumor drugs are based on suppressing the activity of individual members of the signaling cascades maintaining the transformed phenotypes. Therefore, identification of previously unknown functions of signaling protein kinases is important for cancer therapy. Akt kinase is a central player in the majority of these pathways. For example, Akt inhibitor perifosine demonstrated activity in patients with advanced renal cell carcinoma after failure on VEGF-targeted therapy [43]. As well, perifosin demonstrated efficacy in ovarian cancer and endometrial cancer patients [44]. Obviously, under conditions of prodeath Akt activity, as described by us in the current paper, these agents may cause the opposite effects. Thus, it is important to take into consideration all individual functions of an anticancer target in a specific type of cancer.

\section{MATERIALS AND METHODS}

\section{Cell culture and chemicals}

SK-Mel-147 human melanoma cell line was obtained from the Memorial Sloan Kettering Cancer Center. Cells were cultured in DMEM supplemented with $10 \%$ fetal calf serum, $2 \mathrm{mM}$ L-glutamine, penicillin (100 $\mathrm{U} / \mathrm{ml})$, and streptomycin $(100 \mu \mathrm{g} / \mathrm{ml})$ and incubated at $37^{\circ} \mathrm{C}$ in the atmosphere with $5 \% \mathrm{CO}_{2}$. Polyclonal antibodies to the $\alpha 2$-integrin subunit and monoclonal antibodies to the integrin $\alpha 2 \beta 1$ were, respectively, from Chemicon and BD PharMingen. Polyclonal antibodies to protein kinases Akt, ERK, and their phosphorylated forms (pAkt Ser473, pAkt1 Ser473, pAkt2 Ser474, and pERK Thr202/Tyr204) were from Cell Signaling Biotech. Akt isoform specific siRNAs were from Santa Cruz Biotech. PI3K inhibitor, LY294002, Akt1 inhibitor XXIII, Akt2 inhibitor XII, and ERK inhibitor, PD98059, were from Calbiochem, and other chemicals were from Sigma.

\section{Transduction of cells with shRNA}

Bacterial glycerol clones NM_002203.2-1427s1c1 (\#D3) and NM_002203.3-1561s21c1 (\#D7) containing lentiviral plasmid vector pLKO.1-puro with shRNA specific for the $\alpha 2$ - integrin subunit and pLKO.1-puro lentiviral vector without shRNA («empty» vector, control) were purchased from Sigma. Lentivirus was produced in HEK293T cells by co-transfection with shRNA-containing or control vector with packing plasmids as described earlier $[44,45]$. Cells were transduced with lentivirus in the presence of polybrene $(8 \mu \mathrm{g} / \mathrm{ml})$ and selected with puromycin (1-2 $\mu \mathrm{g} / \mathrm{ml})$ for 4-6 days.

\section{siRNA transfection}

siRNA duplexes, both control and specific to the Akt isoforms, as well as siRNA transfection reagent were from Santa Cruz Biotech. (CA, USA). The procedure was performed as described earlier [46]. Briefly, 1-2 $\times$ $10^{5}$ cells in $1 \mathrm{ml}$ of antibiotic-free DMEM $+10 \%$ FBS were plated into each well of 6-well culture plates. After reaching $\sim 50 \%$ confluence the cells were transfected with $50 \mathrm{nM}$ siRNA (final concentration) for $70 \mathrm{~h}$. Then cells were harvested with trypsin/EDTA, washed and used for subsequent experiments.

\section{Anchorage-dependent apoptosis (anoikis)}

Anoikis was assessed by the accumulation of cells with DNA content lower than that of diploid cells (sub-G1 population), after their cultivation on the non-adhesive substrate - polyhydroxyethylmethacrylate (poly-HEMA). The substrate was prepared in 6-well plates according to previously described procedure [34]. $3 \times 10^{5}$ cells/well were incubated in medium containing $10 \%$ fetal serum, at $37^{\circ} \mathrm{C}$ for $24 \mathrm{~h}$ and prepared for FACS analysis. In some experiments, anoikis was assessed by percentage of cells stained in vivo with Trypan Blue, which was determined in an automatic cell analyzer Vi-Cell (Beckman Coulter). Anoikis in these experiments did not differ from that detected by FACS analysis

\section{Clonal activity}

2000 cells were plated on a $1 \%$ methylcellulose gel in complete medium in Petri dishes for 14 days. The colonies were stained with Crystal Violet, visualized in an optical microscope and photographed.

\section{Flow cytometry}

$1 \times 10^{5}$ cells were fixed with $70 \%$ ethanol, rinsed in $\mathrm{PBS}$, resuspended in $1 \mathrm{ml}$ citrate buffer containing 
$50 \mu \mathrm{g} / \mathrm{ml}$ propidium iodide and $10 \mu \mathrm{g} / \mathrm{ml}$ RNAse A, followed by storing on ice for $3 \mathrm{~h}$. Cell surface expression of $\alpha 2 \beta 1$ integrin was assessed by treating the cells with anti- $\alpha 2 \beta 1$ (BD PharMingen), followed by staining with FITC-conjugated secondary antibody and fixation with $2 \%$ formaldehyde. The cells were analyzed using Becton Dickinson flow cytometer.

\section{SDS-PAGE and Western-blotting}

The procedures were performed as described in [34]. $30 \mu \mathrm{g}$ of cell lysate proteins were run on SDS-PAGE and electroblotted onto a PVDF membrane. After reaction with specific primary antibodies, the membrane was incubated with HRP-conjugated secondary antibodies, developed in a ECL detection system (Amersham, England) and imaged on MF-ChemiBis 3.2 (DNR Bio-Imaging Systems).

\section{Statistical analysis}

Differences between the groups were assessed using Student's $t$-test and considered significant at $p<0.05$.

\section{Author contributions}

AEB designed the experiments. AEB and NIK wrote the manuscript. NIK, GEM, NAU performed the experiments. All authors discussed the results and commented on the manuscript.

\section{CONFLICTS OF INTEREST}

All authors declare the absence of any conflicts of interests.

\section{FUNDING}

Cell culture studies, investigations of anoikis and of cell clonal activity were funded by the Program for Basic Research of State Academies of Sciences for 2013-2020; studies based on shRNA and siRNA cell transduction, flow cytometry and western-blotting were funded by the Russian Foundation for Basic Research (grant 17-0400716).

\section{REFERENCES}

1. Fricsh SM, Screaton RA. Anoikis mehanisms. Curr Opin Cell Biol. 2001; 13:555-562.

2. Zhan M, Zhao H, Han ZC. Signalling mechanisms of anoikis. Histol Histopathol. 2004; 19:973-983. https://doi. org/10.14670/HH-19.973.

3. Jenning S, Pham T, Ireland SK, Ruoslahti E, Biliran H. Bit1 in anoikis resistance and tumor metastasis. Cancer Lett. 2013; 333:147-151. https://doi.org/10.1016/j. canlet.2013.01.043.
4. Guo W, Giancotti FG. Integrin signalling during tumour progression. Nat Rev Mol Cell Biol. 2004; 10:816-826. https://doi.org/10.1038/nrm1490.

5. Hehlgans S, Haase M, Cordes N, Signalling via integrins: implications for cell survival and anticancer strategies. Biochim Biophys Acta. 2007; 1775:163-180.

6. Desgrosellier JS, Cheresh DA. Integrins in cancer: biological implications and therapeutic opportunities. Nat Rev Cancer. 2010; 10:9-22. https://doi.org/10.1038/nrc2748.

7. Kuphal S, Bauer R, Bosserhoff AK. Integrin signaling in malignant melanoma. Cancer Metastasis Rev. 2005; 24:195-222. https://doi.org/10.1007/s10555-005-1572-1.

8. Haenssen KK, Caldwell SA, Shahriari KS, Jackson SR, Whelan KA, Klein-Szanto AJ, Reginato MJ. ErbB2 requires integrin alpha 5 for anoikis resistance via Src regulation of receptor activity in human mammary epithelial cells. J Cell Sci. 2010; 123:1373-1382. https://doi.org/10.1242/ jes.050906.

9. Bai J, Zhang J, Wu J, Chen L, Zeng J, Ding J, Wu Y, Gong Z, Xu S, Zhou J, Li G. JWA regulates melanoma metastasis by integrin alphaVbeta3 signaling. Oncogene. 2010; 29:1227-1237. https://doi.org/10.1038/onc.2009.408.

10. Tran T, Barlow B, O'Rear L, Jarvis B, Li Z, Dickeson K, Dupont W, Zutter M. Loss of the $\alpha 2 \beta 1$ integrin alters human papilloma virus-induced squamous carcinoma progression in vivo and in vitro. PLoS One. 2011; 6:e26858. https://doi. org/10.1371/journal.pone.0026858.

11. Niland S, Cremer A, Fluck J, Eble JA, Krieg T, Sollberg S. Contraction-dependent apoptosis of normal fibroblasts. J Invest Dermatol. 2001; 116:686-692. https://doi. org/10.1046/j.1523-1747.2001.01342.x.

12. Sato $\mathrm{Y}$, Morimoto K, Kubo T, Yanagihara K, Seyama T. High mannose-binding antiviral lectin PFL from Pseudomonas fluorescens Pf0-1 promotes cell death of gastric cancer cell MKN28 via interaction with a2-integrin. PLoS One. 2012; 7:e45922. https://doi.org/10.1371/journal. pone. 0045922 .

13. Ferraro A, Mourtzoukou D, Kosmidou V, Avlonitis S, Kontogeorgos G, Zografos G, Pintzas A. EZH2 is regulated by ERK/AKT and targets integrin alpha2 gene to control epithelial-mesenchymal transition and anoikis in colon cancer cells. Int J Biochem Cell Biol. 2013; 45:243-254. https://doi.org/10.1016/j.biocel.2012.10.009.

14. Jinka R, Kapoo R, Pavuluri S, Raj AT, Kumar MJ, Rao L, Pande G. Differential gene expression and clonal selection during cellular transformation induced by adhesion deprivation. BMC Cell Biol. 2010; 11:93. https://doi. org/10.1186/1471-2121-11-93.

15. Okayama H. Cdc6: a trifunctional AAA+ ATPase that plays a central role in controlling the $\mathrm{G}(1)-\mathrm{S}$ transition and cell survival. J Biochem. 2012; 152:297-303. https://doi. org $/ 10.1093 / \mathrm{jb} / \mathrm{mvs} 083$.

16. Benetatos L, Vartholomatos G, Hatzimichael E. Polycomb group proteins and MYC: the cancer connection. Cell 
Mol Life Sci. 2014; 71:257-269. https://doi.org/10.1007/ s00018-013-1426-x.

17. King WG, Mattaliano MD, Chan TO, Tsichlis PN, Brugge JS. Phosphatidylinositol 3-kinase is required for integrinstimulated AKT and Raf-1/mitogen-activated protein kinase pathway activation. Mol Cell Biol. 1997; 17:4406-4418.

18. Paoli P, Giannoni E, Chiarugi P. Anoikis molecular pathways and its role in cancer progression. Biochim Biophys Acta. 2013; 12:3481-3498. https://doi. org/10.1016/j.bbamcr.2013.06.026.

19. Carduner L, Picot CR, Leroy-Dudal J, Blay L, Kellouche S, Carreiras F. Cell cycle arrest or survival signaling through $\alpha v$ integrins, activation of PKC and ERK1/2 lead to anoikis resistance of ovarian cancer spheroids. Exp Cell Res. 2014; 320:329-342. https://doi.org/10.1016/j.yexcr.2013.11.011.

20. Feng XX, Liu M, Yan W, Zhou ZZ, Xia YJ, Tu W, Li $\mathrm{PY}$, Tian DA. $\beta 3$ integrin promotes TGF- $\beta 1 / \mathrm{H} 2 \mathrm{O} 2 /$ HOCl-mediated induction of metastatic phenotype of hepatocellular carcinoma cells by enhancing TGFB1 signaling. PLoS One. 2013; 8:e79857. https://doi. org/10.1371/journal.pone.0079857.

21. Zheng Y, Tyner AL. Context-specific protein tyrosine kinase 6 (PTK6) signalling in prostate cancer. Eur J Clin Invest. 2013; 43:397-404. https://doi.org/10.1111/eci.12050.

22. Desiniotis A, Kyprianou N. Significance of talin in cancer progression and metastasis. Int Rev Cell Mol Biol. 2011; 289:117-147. https://doi.org/10.1016/ B978-0-12-386039-2.00004-3.

23. Kozlova NI, Morozevich GE, Ushakova NA, Berman AE. Implication of integrin $\alpha 2 \beta 1$ in proliferation and invasion of human breast carcinoma and melanoma cells: Noncanonical function of akt protein kinase. Biochemistry (Mosc). 2018; 83:738-745.

24. Toker A. Achieving specificity in Akt signaling in cancer. Adv Biol Regul. 2012; 52:78-87. https://doi.org/10.1016/j. advenzreg.2011.09.020.

25. Riggio M, Perrone MC, Polo ML, Rodriguez MJ, May M, Abba M, Lanari C, Novaro V. AKT1 and AKT2 isoforms play distinct roles during breast cancer progression through the regulation of specific downstream proteins. Sci Rep. 2017; 7:44244. https://doi.org/10.1038/srep44244.

26. Hutchinson JN, Jin J, Cardiff RD, Woodgett JR, Muller WJ. Activation of Akt-1 (PKB-alpha) can accelerate ErbB2-mediated mammary tumorigenesis but suppresses tumor invasion. Cancer Res. 2004; 64:3171-3178.

27. Arboleda MJ, Lyons JF, Kabbinavar FF, Bray MR, Snow BE, Ayala R, Danino M, Karlan BY, Slamon DJ. Overexpression of Akt2/protein kinase Bbeta leads to up-regulation of beta1 integrins, increased invasion, and metastasis of human breast and ovarian cancer cells. Cancer Res. 2003; 63:196-206.

28. Dumble M, Crouthamel MC, Zhang SZ, Schaber M, Levy D, Robell K, Liu Q, Figueroa DJ, Minthorn EA, Seefeld MA, Rouse MB, Rabindran SK, Heerding DA, et al.
Discovery of novel AKT inhibitors with enhanced antitumor effects in combination with the MEK inhibitor. PLoS One. 2014; 9:e100880. https://doi.org/10.1371/journal. pone. 0100880 .

29. Matsunaga T, Takemoto N, Sato T, Takimoto R, Tanaka I, Fujimi A, Akiyama T, Kuroda H, Kawano Y, Kobune M, Kato J, Hirayama Y, Sakamaki S, et al. Interaction between leukemic-cell VLA-4 and stromal fibronectin is a decisive factor for minimal residual disease of acute myelogenous leukemia. Nat Med. 2003; 9:1158-1165. https://doi. org/10.1038/nm909.

30. Marco RA, Diaz-Montero CM, Wygant JN, Kleinerman ES, McIntyre BW. Alpha 4 integrin increases anoikis of human osteosarcoma cells. J Cell Biochem. 2003; 88:1038-1047. https://doi.org/10.1002/jcb.10465.

31. Shen W, Chen D, Fu H, Liu S, Sun K, Sun X. S100A4 protects gastric cancer cells from anoikis through regulation of $\alpha v$ and $\alpha 5$ integrin. Cancer Sci. 2011; 102:1014-1018. https://doi.org/10.1111/j.1349-7006.2011.01915.x.

32. Rohwer N, Welzel M, Daskalow K, Pfander D, Wiedenmann B, Detjen K, Cramer T. Hypoxia-inducible factor 1alpha mediates anoikis resistance via suppression of alpha5 integrin. Cancer Res. 2008; 68:10113-10120. https://doi. org/10.1158/0008-5472.CAN-08-1839.

33. Plath T, Detjen K, Welzel M, von Marschall Z, Murphy D, Schirner M, Wiedenmann B, Rosewicz S. A novel function for the tumor suppressor p16(INK4a): induction of anoikis via upregulation of the alpha(5)beta(1) fibronectin receptor. J Cell Biol. 2000; 150:467-1478.

34. Morozevich GE, Kozlova NI, Susova OY, Karalkin PA, Berman AE. Implication of $\alpha 2 \beta 1$ integrin in anoikis of MCF-7 human breast carcinoma cells. Biochemistry (Mosc). 2015; 80:97-103. https://doi.org/10.1134/S0006297915010113.

35. Damsky CH, Ilic D. Integrin signaling: it's where the action is. Curr Opin Cell Biol. 2002; 14:594-602.

36. Soung YH, Clifford JL, Chung J. Crosstalk between integrin and receptor tyrosine kinase signaling in breast carcinoma progression. BMB Rep. 2010; 43:311-318.

37. Wang M, Fu Z, Wu J, Zhang J, Jiang L, Khazan B, Telljohann R, Zhao M, Krug AW, Pikilidou M, Monticone RE, Wersto R, Van Eyk J, Lakatta EG. MFG-E8 activates proliferation of vascular smooth muscle cells via integrin signaling. Aging Cell. 2012; 11:500-508. https://doi. org/10.1111/j.1474-9726.2012.00813.x.

38. Choi JA, Jung YS, Kim JY, Kim HM, Lim IK. Inhibition of breast cancer invasion by TIS21/BTG2/Pc3-Akt1-Sp1Nox4 pathway targeting actin nucleators, mDia genes. Oncogene. 2016; 35:83-93.

39. Blagosklonny MV, Schulte T, Nguyen P, Trepel J, Neckers LM. Taxol-induced apoptosis and phosphorylation of Bcl-2 protein involves c-Raf-1 and represents a novel c-Raf-1 signal transduction pathway. Cancer Res. 1996; 56:1851-1854.

40. Fehrenbacher N, Bastholm L, Kirkegaard-Sorensen T, Rafn B, Bøttzauw T, Nielsen C, Weber E, Shirasawa S, 
Kallunki T, Jäättelä M. Sensitization to the lysosomal cell death pathway by oncogene-induced down-regulation of lysosome-associated membrane proteins 1 and 2 . Cancer Res. 2008; 68:6623-6633. https://doi.org/10.1158/00085472.CAN-08-0463.

41. Liu J, Mao W, Ding B, Liang CS. ERKs/p53 signal transduction pathway is involved in doxorubicin-induced apoptosis in H9c2 cells and cardiomyocytes. Am J Physiol Heart Circ Physiol. 2008; 295:H1956-H1965.

42. Brozovic A, Osmak M. Activation of mitogen-activated protein kinases by cisplatin and their role in cisplatinresistance. Cancer Lett. 2007; 251:1-16.

43. Cho DC, Hutson TE, Samlowski W, Sportelli P, Somer B, Richards P, Sosman JA, Puzanov I, Michaelson MD, Flaherty KT, Figlin RA, Vogelzang NJ. Two phase 2 trials of the novel Akt inhibitor perifosine in patients with advanced renal cell carcinoma after progression on vascular endothelial growth factor-targeted therapy. Cancer. 2012; 118:6055-6062. https://doi.org/10.1002/cncr.27668.
44. Hasegawa K, Kagabu M, Mizuno M, Oda K, Aoki D, Mabuchi S, Kamiura S, Yamaguchi S, Aoki Y, Saito T, Yunokawa M, Takehara K, Okamoto A, et al. Phase II basket trial of perifosine monotherapy for recurrent gynecologic cancer with or without PIK3CA mutations. Invest New Drugs. 2017; 35:800-812. https://doi. org/10.1007/s10637-017-0504-6.

45. Morozevich GE, Kozlova NI, Ushakova NA, Preobrazhenskaya ME, Berman AE. Integrin $\alpha 5 \beta 1$ simultaneously controls EGFR-dependent proliferation and Akt-dependent pro-survival signaling in epidermoid carcinoma cells. Aging (Albany NY). 2012; 4:368-374. https://doi.org/10.18632/aging.100457.

46. Morozevich G, Kozlova N, Cheglakov I, Ushakova N, Berman A. Integrin $\alpha 5 \beta 1$ controls invasion of human breast carcinoma cells by direct and indirect modulation of MMP-2 collagenase activity. Cell Cycle. 2009; 8:2219-222. 